\title{
Optimization of electric networks modes under conditions of partial uncertainty of initial information
}

\author{
Kamal Reymov ${ }^{1}$, S. K. Makhmuthonov², Gulnaz Turmanova ${ }^{1}$, Quwat Uzaqbaev $^{1}$ \\ ${ }^{1}$ Karakalpak State University, Nukus, Uzbekistan \\ ${ }^{2}$ Tashkent state technical university named after Islam Karimov, Tashkent, Uzbekistan
}

\begin{abstract}
One of the problems of modern power systems management regimes associated with the probabilistic nature of the starting information. In such circumstances, the decision of relevant control tasks based on deterministic methods lead to unacceptable or non-optimal results. Therefore, this article questions optimization of energy systems based on functional limitations in terms of probability of the initial information
\end{abstract}

\section{Introduction}

Currently, most of the methods and algorithms for calculating and analyzing the modes of electric power systems are based on the use of deterministic models. In this case, the nature of the ongoing process is determined unambiguously for the given schemes and operating parameters. Such models are characterized by high accuracy and speed, all influencing factors are taken into account as much and accurately as possible. However, to assess any one or several parameters based on this model, each time it is required to carry out calculations according to the full scheme with the appropriate preparation of the initial data and a greater cost of estimated time. At the same time, it does not seem possible to take into account all influencing factors, especially the probabilistic nature of the initial information. Therefore, the calculation result with the corresponding error reduces the effect of solving the problem [1-7].

In this regard, the issues of synthesis of control laws for limited information are topical. To solve these questions, regression models can be effectively used, the features of which are the establishment of statistical links between the controlled parameters and the factors influencing them.. In the tasks of optimizing the modes of electrical networks, such parameters are most often taken to be the optimized parameters - the voltages of the reference nodes, the reactive powers of the controlled sources and the transformation ratios of the controlled transformers [8-15].

\section{The mathematical statement of the problem}

In such problems, the coefficients of the regression equations are determined in advance on the basis of regression analysis and the use of an appropriate approximation method, most often the least squares method. This paper presents the results of research on the modes of electrical networks under conditions of partial uncertainty of the initial information. A quadratic equation is taken as a regression equation. The factors were the loads of the nodes. Optimized parameters - voltages of nodes with adjustable reactive powers - are accepted as responses. The regression equation for the optimized node stress is as follows:

$$
U_{i}=a_{i o}+\sum_{j=1}^{n} i j P_{j}+\sum_{j=1}^{n} \sum_{k=j}^{n} a_{i j k} P_{j} P_{k}
$$

Where $\mathrm{n}$ is the number of nodes in the electrical network, $a_{i 0}, a_{i j}, a_{i j k}$-the coefficients of the regression equation, which determines the coefficients of the regression equations, the values of the load factors of the nodes were set in a certain range by a random number generator. And the correspondence of the response value was determined on the basis of optimization by the deterministic method [16-24].

The work investigated the dependence of the accuracy of the regression model on the number of experiments (number of samples). The results of the experimental calculations for various typical schemes of electrical networks showed that to determine the coefficients of the regression equations, at which the process under study is modeled with sufficient accuracy for practical purposes, it is advisable to use experimental planning methods with the adoption for each factor in a given range of three values minimum, average and maximum. In this case, the number of necessary experiments is equal to $3 n$, where $n$ is the number of factors (nodes with partially undefined loads) .

\section{Modelling of redundant scheme of energy source structure}

The studies, in particular, were carried out for the electrical network, the diagram of which is shown in Pic. 1. 
The loads of nodes 1, 4 and 7 are partially undefined. The minimum and maximum possible active loads and $\operatorname{tg} \varphi$ for these nodes are given in Table 1.

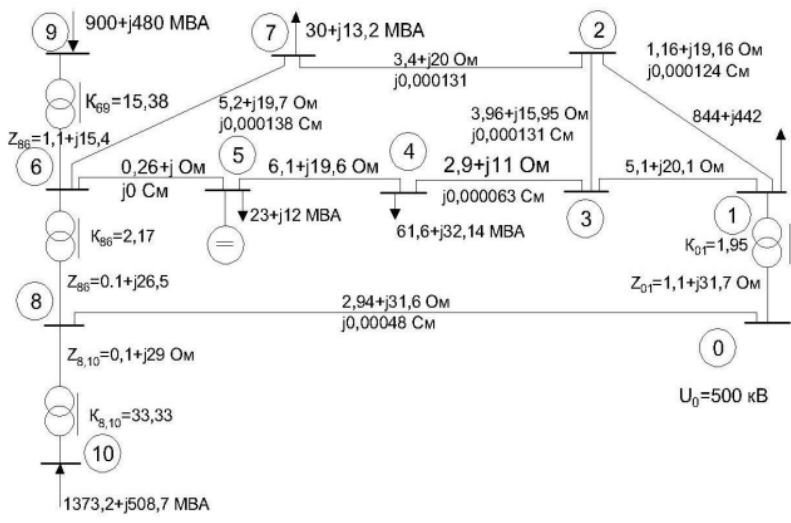

Fig. 1. Electrical network diagram

Table 1. Load of nodes

\begin{tabular}{|c|c|c|c|}
\hline & $\mathrm{P}_{1}, \mathrm{MW}$ & $\mathrm{P}_{4,} \mathrm{MW}$ & $\mathrm{P}_{7,} \mathrm{MW}$ \\
\hline Minimum & 801,8 & 55,4 & 27 \\
\hline Average & 844,0 & 61,6 & 30 \\
\hline Maximum & 886,2 & 67,76 & 33 \\
\hline $\operatorname{tg} \varphi$ & 0,5236 & 0,5217 & 0,4403 \\
\hline
\end{tabular}

Optimization of the electrical network mode is carried out according to the voltages of nodes 5 and 9 where there are adjustable sources of reactive power.

Below are the regression equations, the coefficients of which were obtained on the basis of a statistical experiment with the number of samples of 500 and the method of experiment planning.

1) based on a statistical experiment with 500 samples:

$U_{5}=220,83+0,0413 \cdot P_{1}+0,3582 \cdot P_{4}-0,0343 \cdot P_{7}-$ $0,00011074 \cdot P_{1}{ }^{2}+0,00078887 \cdot P_{1} P_{4}++0,00087082$. $P_{1} P_{7}-0,00574887 \cdot P_{4}{ }^{2}+0,00182516 \cdot P_{4} P_{7}-$ $0,0119837 \cdot P_{7}^{2}$.

$\mathrm{U}_{9}=15,2-0,000004 \cdot \mathrm{P}_{1}-0,00001 \cdot \mathrm{P}_{4}-0,000023 \cdot \mathrm{P}_{7}+$ $0,000000002 \cdot P_{1}^{2}+0,000000006 \cdot \mathrm{P}_{1} \mathrm{P}_{4}+0.000000017 \cdot \mathrm{P}_{1} \mathrm{P}_{7}$ $+0,000000031 \cdot P_{4}^{2}+0,000000059 \cdot \mathrm{P}_{4} \mathrm{P}_{7}+0,000000086$. $P_{4}^{2}$.

2) experiment planning method:

$U_{5}=112,72+0,775 \cdot P_{1}+17,63 \cdot P_{4}-0,7584 \cdot P_{7}-$ $0,00055488 \cdot P_{1}^{2}+0,00097513 \cdot P_{1} P_{4}++0,000776$. $P_{1} P_{7}-0,01980088 \cdot P_{4}{ }^{2}+0,00428843 \cdot P_{4} P_{7}-$ $0,0023226 \cdot P_{7}^{2}$.

$\mathrm{U}_{9}=15,2-0,000001 \cdot \mathrm{P}_{1}-0,0000004 \cdot \mathrm{P}_{4}-0,0000005 \cdot \mathrm{P}_{7}$ $+6,65 \cdot P_{1}^{2}+0,000000006 \cdot \mathrm{P}_{1} \mathrm{P}_{4}+0.000000017 \mathrm{P}_{1} \mathrm{P}_{7}+$ $0,000000031 P_{4}^{2}+0,000000059 \mathrm{P}_{4} \mathrm{P}_{7}+0,000000086$. 1011. $P_{1}^{2}+2,3 \cdot 10^{-10} \cdot \mathrm{P}_{1} \mathrm{P}_{4}+2,6 \cdot 10^{-10} \cdot \mathrm{P}_{1} \mathrm{P}_{7}++1,46 \cdot 10^{-}$ $9 \cdot P_{4}^{2}+1,3 \cdot 10^{-9} \cdot \mathrm{P}_{4} \mathrm{P}_{7}+3,55 \cdot 10^{-9} \cdot P_{7}^{2}$.

The verification of the adequacy of the regression equations was carried out on the basis of calculating the total losses in the networks by carrying out optimization according to the complete scheme of the electrical network and determining the optimal voltages for the nodes by the obtained regression equations for various values of the loads of nodes 1,4 , and 7 .

The root-mean-square deviation of the total losses of active power in the networks when using the regression equations turned out to be less than $0.1 \%$, which quite satisfies the requirements of practical calculations.

Table 2 contains the results of optimization of the modes of electrical networks for some specific values of the loads of nodes 1,4 , and 7 according to the full scheme based on a deterministic algorithm and using regression equations with coefficients obtained when planning an experiment [25-37].

Table 2. Optimization results

\begin{tabular}{|c|c|r|r|r|r|r|r|r|}
\hline \multicolumn{2}{|c|}{$\begin{array}{c}\text { Loads of } \\
\text { nodes, } \\
\text { MW }\end{array}$} & \multicolumn{3}{c|}{$\begin{array}{c}\text { Full-scheme } \\
\text { optimization }\end{array}$} & \multicolumn{3}{c|}{$\begin{array}{c}\text { Optimization } \\
\text { based on a } \\
\text { regression model }\end{array}$} \\
\hline & & $\mathrm{P}$ & $\begin{array}{c}\mathrm{U}_{5}, \\
\mathrm{P}_{1}\end{array}$ & $\begin{array}{c}\mathrm{U} \\
\mathrm{P}_{4}\end{array}$ & $\begin{array}{c}\pi \\
\mathrm{M}\end{array}$ & $\begin{array}{r}\mathrm{U}_{5}, \\
\mathrm{kV}\end{array}$ & $\begin{array}{c}\mathrm{U} \\
9 \\
\mathrm{kV}\end{array}$ & $\begin{array}{c}\pi \\
\mathrm{M} \\
\mathrm{WV}\end{array}$ \\
\hline 80 & 61 & 3 & 23 & 1 & 80, & 23 & 1 & 80, \\
1,8 &, 6 & 3,0 & 5,50 & 5,2 & 892 & 5,28 & 5,2 & 944 \\
\hline 88 & 61 & 2 & 22 & 1 & 84, & 22 & 1 & 84, \\
6,2 &, 6 & 7,0 & 8,82 & 5,2 & 195 & 8,54 & 5,2 & 316 \\
\hline 84 & 67 & 3 & 23 & 1 & 81, & 22 & 1 & 81, \\
4,0 &, 76 & 0,0 & 5,16 & 5,2 & 486 & 3,96 & 5,2 & 791 \\
\hline
\end{tabular}

\section{Conclusions}

Thus, the results obtained confirm that the adopted regression model has a sufficiently high calculation accuracy and allows one to determine the optimal values of the controlled parameters (in this case, the voltages of nodes 5 and 9), even in conditions of insufficient information required for optimization according to the complete circuit of the electrical network.

\section{References}

1. Molderink, A. Management and control of domestic smart grid technology / A. Molderink, V. Bakker, M.G.C. Bosman, J.L. Hurink, G.J.M. Smit// IEEE Trans.Smart Grid. - 2010. №2. - pp.109-119.

2. Ravibabu, P. An approach of DSM techniques for domestic load management using fuzzy logic / P. Ravibabu, A. Praveen, C.V. Chandra, P.R. Reddy, M. Teja// EEE International Conference of Fuzzy Systems, 2009. - pp.13031307.

3. M.K. Bakhadyrkhanov, G.Kh. Mavlonov, S. B. Isamov, K.S. Ayupov, H.M. Iliev O.E. Sattarov, S.A. Tachilin. Photoconductivity of silicon with multiply charged clusters of manganese atoms [Mn]4 // Surface Engineering and Applied Electrochemistry 46 (3), 276-280.

4. Ludwig G.W., Woodbury H.H., Carlson R.O. // J. Phys. Chem. Sol. 1959. V.8.P.490.

5. Kreissl, J. and Gehlhaff, W., Electron Paramagnetic Resonance of the Cluster in Silicon, Phys. Status solidi B, 1988, vol. 145, P. 609.

6. Bakhadyrkhanov M.K., Ismailov K.A., Ismaylov B.K., Saparniyazova Z.M. Clusters of nickel atoms and controlling their state in silicon lattice// Semiconductor Physics, 
Quantum Electronics \& Optoelectronics, 2018 V. 21, No. 4. P. 392-396.

7. Watkins G.D. An E.P.R. Study of the lattice vacancy in silicon. J. Phys. Soc. Jap., 1963.18, No. III, P. 22-27.

8. Watkins G.D., Corbett I.W. Defects in irradiated silicon, electron paramagnetic of the divacancy. Phys. Rev., 1965, 138.

9. F.A.Hoshimov, I.I.Bakhadirov, M.S.Kurbanbayeva, N.A.Aytbayev. Development of specific standards of energy consumption by types of produced products of the spinning product // RSES 2020. E3S Web of Conferences. 216 (2020) 01169. https://doi.org/10.1051/e3sconf/202021601169

10. F.A.Hoshimov, I.I.Bakhadirov, A.A.Alimov, M.T.Erejepov. Forecasting the electric consumption of objects using artificial neural networks // E3S Web of Conferences. $216 \quad 01170$. https://doi.org/10.1051/e3sconf/202021601170

11. I.U.Rakhmonov, F.A.Hoshimov. Development of an algorithm for evaluating the dominant factors that have the greatest impact on the energy intensity of products // ENERGY-21. E3S Web of Conferences. 209 (2020) 07018. https://doi.org/10.1051/e3sconf/202020907018

12. Usmanov E.G. Stability in a parallel resonant circuit with active load // RSES 2020. E3S Web of Conferences. 216 (2020) 01160. https://doi.org/10.1051/e3sconf/202021601160 13. Usmanov E.G., Khusanov B.M. Phase relations in resonant circuits with a wide falling section on the amplitude characteristic // RSES 2020. E3S Web of Conferences. 216 (2020) 01161. https://doi.org/10.1051/e3sconf/202021601161 14. I.U.Rakhmonov, K.M.Reymov. Statistical models of renewable energy intermittency // RSES 2020. E3S Web of Conferences. $216 \quad 01167$. https://doi.org/10.1051/e3sconf/202021601167

15. I.U.Rakhmonov, N.N.Kurbonov. Analysis of automated software for monitoring energy consumption and efficiency of industrial enterprises // E3S Web of Conferences. 216 (2020) 01178. https://doi.org/10.1051/e3sconf/202021601178 16. F.A.Hoshimov, I.U.Rakhmonov, N.N.Niyozov. Technology to reduce energy costs in the electric steel melting shop // ENERGY-21. E3S Web of Conferences. 209 (2020) 07017. https://doi.org/10.1051/e3sconf/202020907017 17. A.Taslimov, F.Rakhimov, L.Nematov, N.Markaev, A.Bijanov, R.Yunusov. Economic load intervals for selecting $10 \mathrm{kV}$ cable cross-sections for agricultural consumers // CONMECHYDRO - 2020. IOP Conf. Series: Materials Science and Engineering. $883 \quad$ (2020) 012102. doi:10.1088/1757-899X/883/1/012102

18. A.Taslimov, M.Melikuziev, O.Matchonov, M.Ruzinazarov and M.Nasirov. Development of standard cable cross-sections of rural electrical networks // CONMECHYDRO - 2020. IOP Conf. Series: Materials Science and Engineering. $883 \quad$ (2020) 012105. doi:10.1088/1757-899X/883/1/012105

19. I.Bakhadirov, N.Markaev, G.Aslanova, R.Tanatarov, S.Makhmuthonov. Differentiated tariffs of electricity for the improvement of steelmaking Uzbekistan // CONMECHYDRO - 2020. IOP Conf. Series: Materials Science and Engineering. 883 (2020) 012121. doi:10.1088/1757-899X/883/1/012121

20. A.D.Taslimov, A.S.Berdishev, F.M.Rakhimov and A.A.Yuldashev. Optimal tendency of selecting cable crosssections for agricultural electrical networks // ICMSIT-2020.
Journal of Physics: Conference Series. 1515 (2020) 022056. doi:10.1088/1742-6596/1515/2/022056

21. A.D.Taslimov. Selection of a complex of parameters of distribution electric networks with respect to technical limitations // ENERGY-21. E3S Web of Conferences. 209 (2020) 07013. https://doi.org/10.1051/e3sconf/202020907013 22. K.M.Reymov, G.R.Rafikova, L.A.Nematov, Sh.Esemuratova. Existing condition and prospects of making power balance and managing load of electric consumers in uzbek power system // ENERGY-21. E3S Web of Conferences. $\quad 209 \quad 07015$. https://doi.org/10.1051/e3sconf/202020907015

23. A.D.Taslimov, F.M.Rakhimov, A.O.Norkulov, A.A.Yuldashev. Research of the optimum scale of standard sections of agricultural purpose lines // E3S Web of Conferences. $216 \quad 01158$. https://doi.org/10.1051/e3sconf/202021601158

24. A.D.Taslimov., M.V.Melikuziev, A.M.Najimova, A.A.Alimov. Economic load intervals for selection of cable sections for agricultural purpose // E3S Web of Conferences. $216 \quad 01159$. https://doi.org/10.1051/e3sconf/202021601159

25. Olimjon Toirov,Kamoliddin Alimkhodjaev, Nurali Pirmatov and Aziza Kholbutaeva E3S Web of Conferences 216, 01119 https://doi.org/10.1051/e3sconf/202021601119

26. Hadha Afrisal, Budi Setiyono, Muhammad Fahmi Yusuf, Rose Mutiara Suin, Olimjon Toirov 2020 7th International Conference on Information Technology, Computer, and Electrical Engineering (ICITACEE), pp. 4146 (2020),

https://doi.org/10.1109/ICITACEE50144.2020.9239228

27. Kamoliddin Alimkhodjaev, Olimjon Toirov, Mirzohid Taniev, Sharofiddin Alimkhodjaev Addressing Issues and Possibility of Introducing Renewable Energy Sources in the Conditions of Uzbekistan. JCR. 7(15), 1721-1728 (2020), doi:10.31838/jcr.07.15.231

28. Olimjon Toirov, Tulyagan Kamalov, Utkir Mirkhonov, Sardor Urokov, Dilnoza Jumaeva The mathematical model and a block diagram of a synchronous motor compressor unit with a system of automatic control of the excitation, E3S Web of Conferences, SUSE-2021 (2021)

29. Olimjon Toirov, Sardor Urokov, Utkir Mirkhonov, Hadha Afrisal, Dilnoza Jumaeva Experimental study of the control of operating modes of a plate feeder based on a frequency-controlled electric drive, E3S Web of Conferences, SUSE-2021 (2021)

30. Haqberdiev A., Toshov J. Analysis of the control system of electric motors of the running gear of self-propelled mine cars used in complex mining and technological conditions // E3S Web of Conferences 216, 01135 (2020), Rudenko International Conference "Methodological problems in reliability study of large energy systems" (RSES 2020), https://doi.org/10.1051/e3sconf/202021601135

31. K.M.Reymov, G.Turmanova, S.Makhmuthonov, B.Uzakov. Mathematical models and algorithms of optimal load management of electrical consumers // E3S Web of $\begin{array}{llll}\text { Conf. } & 216 & \text { (2020) } & 01166 .\end{array}$ https://doi.org/10.1051/e3sconf/202021601166

32. Yu.M.Bobozhonov, K.M.Reymov, B.T.Seytmuratov, T.Kh.Khakimov. Research of the dependence of the resistance of asynchronous generators with massive rotors on 
their design // RSES 2020. E3S Web of Conferences. 216 (2020) 01168. https://doi.org/10.1051/e3sconf/202021601168 33. A.N.Rasulov, M.R.Ruzinazarov, N.Toirova, T.Sh.Alibekova. Graphical-analytical method for constructing load characteristics // RSES 2020. E3S Web of
Conferences.
216
(2020)
01171.

https://doi.org/10.1051/e3sconf/202021601171

34. Yu.Bobozhonov, B.Seytmuratov, B.Fayzullaev, A.Sultonov. Study of the influence of different designs of massive rotor of asynchronous generator on their maximum power // RSES 2020. E3S Web of Conferences. 216 (2020) 01177. https://doi.org/10.1051/e3sconf/202021601177

35. Karimov R.Ch., Bobojanov M.K., Rasulov A.N., Usmanov E.G. Controlled switching circuits based on nonlinear resistive elements (E3S Web of Conferences, 139, 01039, 2019), https://doi.org/10.1051/e3sconf/201913901039 36. Toshov J.B. The questions of the dynamics of drilling bit on the surface of well bottom// Arch. Min. Sci. - Poland. Vol. 61 (2016), № 2, P. 279-287. DOI 10.1515/amsc-20160020

37. Toshov Zh.B. Ways towards optimization of washout components of rock cutting tools // «GORNYI ZHURNAL»/«MINING JOURNAL», Moscow, 2016, № 2, pp. 21-24. DOI: http://dx.doi.org/10.17580/gzh. 